\title{
Patterns in current perioperative practice: survey of colorectal surgeons in five northern European countries
}

Kristoffer Lassen, Pascal Hannemann, Olle Ljungqvist, Ken Fearon, Cornelis H C Dejong, Maarten F von Meyenfeldt, Jonatan Hausel, Jonas Nygren, Jens Andersen, Arthur Revhaug, on behalf of the Enhanced Recovery After Surgery (ERAS) Group

Editorial by Urbach and Baxter

Department of Gastrointestinal Surgery, University Hospital of Northern Norway, 9038

Troms $\varnothing$, Norway Kristoffer Lassen consultant surgeon Arthur Revhaug professor of surgery

Department of Surgery, University Hospital Maastricht, Maastricht 6202 AZ, Netherlands

Maarten F von

Meyenfeld

professor of surgery

Cornelis H C Dejong

consultant surgeon

Pascal Hannemann

surgical registrar

Centre for Surgical Sciences, Division of Surgery, Karolinska University Hospital, Stockholm, Sweden Olle Ljungqvist professor of surgery

Jonas Nygren associate professor of surgery

Jonatan Hausel doctoral student

Clinical and Surgical Sciences (Surgery), School of Clinical

Sciences and

Community Health, University of

Edinburgh,

Edinburgh EH16 4SA

Ken Fearon

professor of surgery

Department of

Surgical

Gastroenterology,

435 Hvidovre

University Hospital,

Hvidovre 2650,

Denmark

Jens Andersen

consultant surgeom

Correspondence to:

K Lassen

lassen@unn.no

BMJ 2005;330:1420-1
Evidence for optimal perioperative care in colorectal surgery is abundant. By avoiding fasting, intravenous fluid overload, and activation of the neuroendocrine stress response, postoperative catabolism is reduced and recovery enhanced. The specific measures that can be used routinely include no bowel preparation, epidural anaesthesia/analgesia continued for one to two days postoperatively, no nasogastric decompression tube postoperatively, intravenous fluid/saline restriction, and free oral intake from postoperative day one. ${ }^{1-5}$ This survey aimed to characterise perioperative practice in colorectal cancer surgery in five northern European countries: Scotland, the Netherlands, Denmark, Sweden, and Norway.

\section{Participants, methods, and results}

We mailed a questionnaire to the head surgeons of all digestive surgical centres in the five countries of the departments belonging to the Enhanced Recovery After Surgery (ERAS) Group in late spring 2003. We presented a hypothetical case of elective laparotomy with colonic resection for cancer in an otherwise healthy 70 year old man. We asked the respondents to answer according to the practice most widely used in their department at that time.

The table shows the results (fuller version on bmj.com). Response rate was $76 \%$ (200 centres). Oral bowel preparation was still the rule in all countries. The nasogastric decompression tube was widely used postoperatively only in the Netherlands. "Nil by mouth" was hardly used in Scandinavia but was common in the Netherlands and Scotland. By postoperative day one, patients ate at will in $85 \%$ of Danish units and in almost half of units in Norway, the Netherlands, and Sweden. In Scotland, only a quarter of units allowed free eating on day one. The use of epidural analgesia in general

A fuller version of the table is on bmj.com

This article was posted on bmj.com on 23 May 2005: http://bmj.com/cgi/ doi/10.1136/bmj.38478.568067.AE

Responses (percentages) to questionnaire on perioperative care in colonic resections in five northern European countries

\begin{tabular}{lccccc} 
Responses & \multicolumn{1}{c}{ Scotland } & Netherlands & Sweden & Norway & Denmark \\
\hline Response rate & $72.4 \quad(n=55)$ & $83.7 \quad(n=36)$ & $68.3(n=43)$ & $92.7 \quad(n=38)$ & $70.0(n=28)$ \\
\hline For an elective left sided ${ }^{*}$ hemicolectomy for cancer, would bowel preparation be administered? & &
\end{tabular}

For an elective left sided ${ }^{*}$ hemicolectomy for cancer, would bowel preparation be administered?

\begin{tabular}{|c|c|c|c|c|c|}
\hline No & 4 & 18 & 3 & 5 & 19 \\
\hline Yes, oral purgative & 85 & 52 & 95 & 89 & 62 \\
\hline Yes, enema & 4 & 12 & 0 & 3 & 15 \\
\hline Yes, both & 8 & 18 & 3 & 3 & 4 \\
\hline \multicolumn{6}{|c|}{ Is nasogastric decompression tube routinely left in place for more than four hours after surgery? } \\
\hline No & 75 & 22 & 83 & 82 & 85 \\
\hline Until next morning & 12 & 36 & 17 & 18 & 11 \\
\hline Two days or more & 12 & 17 & 0 & 0 & 0 \\
\hline Until bowel movement & 2 & 25 & 0 & 0 & 4 \\
\hline
\end{tabular}

s epidural analgesia used routinely postoperatively after transfer to general ward? (Not high dependency ward/intensive care unit)

\begin{tabular}{lllccc}
\hline Yes & 11 & 83 & 93 & 89 & 96 \\
\hline No & 89 & 17 & 7 & 11 & 4
\end{tabular}

Are there any restrictions on routine intravenous clear fluid administration in the first 72 hours after surgery?

\begin{tabular}{ccccccc}
\hline Yes & $24 \dagger$ & 14 & 5 & 8 & 4 \\
\hline No & 76 & 86 & 95 & 92 & 96
\end{tabular}

Are there any restrictions on routine intravenous sodium administration in the first 72 hours after surgery?

\begin{tabular}{ccccccc}
\hline Yes & $26 \dagger$ & 14 & 0 & 8 & 7 \\
\hline No & 74 & 86 & 100 & 92 & 93 \\
\hline
\end{tabular}

How long would a patient be "nil by mouth" (less than $450 \mathrm{ml}$ clear fluid) postoperatively?

\begin{tabular}{|c|c|c|c|c|c|}
\hline 0 days & 38 & 58 & 71 & 82 & 96 \\
\hline 1-2 days & 46 & 39 & 26 & 18 & 4 \\
\hline 3-4 days & 17 & 3 & 2 & 0 & 0 \\
\hline \multicolumn{6}{|c|}{ When would patients be allowed to resume oral intake at will for solids (eat freely)? } \\
\hline Operating day & 10 & 3 & 12 & 8 & 41 \\
\hline Postoperative day one & 17 & 43 & 32 & 45 & 44 \\
\hline At bowel sounds & 13 & 11 & 23 & 5 & 0 \\
\hline At passage of gas & 44 & 17 & 27 & 32 & 15 \\
\hline Bowel movement & 17 & 26 & 7 & 11 & 0 \\
\hline
\end{tabular}

Results are percentages after exclusion of missing or ambiguous responses (overall $2.55 \%$ excluded). Percentage is of the total numbers of responses to that question.

${ }^{\star}$ The only question in which colonic resection was further specified.

†Scottish centres declaring a fluid/sodium restricting routine allowed maximum values of $3000 \mathrm{ml}$ water and $154 \mathrm{mmol}$ sodium per 24 hours (median). 


\section{What is already known on this topic}

For colonic surgery, current evidence advocates no bowel preparation, epidural anaesthesia/analgesia for 1-2 days postoperatively, no nasogastric decompression tube postoperatively, avoidance of sodium/water overload, and free oral intake from postoperative day one

\section{What this study adds}

Perioperative routines in colonic cancer surgery differ widely in northern Europe and deviate considerably from the best available evidence

wards exceeded 90\% in Scandinavia compared with $11 \%$ in Scotland. Intravenous fluids were used unrestrictedly.

\section{Comment}

Perioperative routines in colorectal cancer treatment in northern Europe differ substantially from evidence based practice. Patients are uniformly subjected to the unpleasant, unnecessary, and harmful practice of preoperative bowel preparation, ${ }^{1}$ precluding oral nutrition and increasing dependency on intravenous fluids. For too many patients, the situation is aggravated as nasogastric tubes are left in place for too long, patients are kept nil by mouth too long, intravenous fluids are administered unrestrictedly, and adequate blocking of pain and afferent stress stimuli is not provided.

The Dutch have implemented postoperative epidural anaesthesia/analgesia in general wards, and their patients should thus be optimally prepared to tolerate a normal diet soon after surgery. ${ }^{2}{ }^{5}$ Nevertheless, in almost half the Dutch centres nasogastric tubes were left in place for two days or more. Of centres where nasogastric tubes were removed early, a third still prescribed nil by mouth for at least a day. Approximately $25 \%$ of Dutch centres did not allow patients to eat solid food at will until bowel movements occurred, and many did not even allow fluids. One could argue that the Dutch have introduced a novel modality but failed to exploit its major potential. In Scotland, a conservative view by anaesthetists prevented patients with epidural anaesthesia/analgesia being nursed outside of high dependency units. This may also have caused the Scottish centres to practise nil by mouth more widely than the others and to withhold both fluids and solids accordingly, although it contrasts with available evidence. $^{5}$
A restricted fluid regimen aiming at unchanged body weight may reduce complications after elective colorectal surgery. ${ }^{4}$ Scotland had the only substantial group claiming such practice. However, the volume of fluids allowed (table) indicates an inadequate reduction as it is twice as high as in the unrestricted (standard) group in the study by Brandstrup et al (median $1500 \mathrm{ml} / 24$ hours).

In spite of a large evidence base for perioperative care aiming to alleviate postoperative catabolism and organ dysfunction, surgical patients remain exposed to unnecessary starvation, suboptimal stress reduction, and fluid overload.

We thank the Scottish Chapters, Associations of Coloproctology and Upper GI Surgeons, the Surgical Society of Sweden, the Dutch Society for Gastrointestinal Surgery, and the Norwegian Society for Digestive Surgery. Preliminary data from this study have been presented as an abstract to the XXXVI Nordic Meeting of Gastroenterology (Oslo, June 2004) and as a lecture to the 26th ESPEN congress (Lisbon, September 2004).

Contributors: KL participated in the planning of the survey, constructed the questionnaire, collected national data, did the analysis, wrote and reviewed the manuscript, and participated in the choice of journal. He is guarantor. All other authors participated in the planning of the survey, construction of the questionnaire, collection of national data, reviewing of the manuscript, and choice of journal.

Funding: None. The ERAS Group is supported by an unrestricted grant from Nutricia Healthcare, which was aware of the planned survey and did not take part in the collecting, analysis, or interpretation of the data reported herein. The decision to publish and the choice of journal are entirely those of the authors. CHCD is supported by a grant from the Dutch Organisation for Scientific Research (NWO Clinical Fellowship 907-00-033). OL and JN are supported by the Swedish Medical Research Council (\#09101).

Competing interests: OL owns some stock in Royal Numico (the mother company for Nutricia) and has a research grant from them.

1 Wille-Jorgensen P, Guenaga KF, Castro AA, Matos D. Clinical value of preoperative mechanical bowel cleansing in elective colorectal surgery: a systematic review. Dis Colon Rectum 2003;46:1013-20.

2 Kehlet $\mathrm{H}$. Modification of responses to surgery by neural blockade: clinical implications. In: Cousins MJ, Bridenbaugh PO, eds. Neural blockade in clinical anesthesia and management of pain. Philadelphia: Lippincott, 1998:129-75.

3 Cheatham ML, Chapman WC, Key SP, Sawyers JL. A meta-analysis of selective versus routine nasogastric decompression after elective laparotomy. Ann Surg 1995;221:469-76.

4 Brandstrup B, Tonnesen H, Beier-Holgersen R, Hjortso E, Ording H, Lindorff-Larsen $\mathrm{K}$, et al. Effects of intravenous fluid restriction on postoperative complications: comparison of two perioperative fluid regimens: a randomized assessor-blinded multicenter trial. Ann Surg 2003;238:641-8

5 Lewis SJ, Egger M, Sylvester PA, Thomas S. Early enteral feeding versus "nil by mouth" after gastrointestinal surgery: systematic review and metaanalysis of controlled trials. BMJ 2001;323:773-6.

(Accepted 25 April 2005)

doi 10.1136/bmj.38478.568067.AE

\section{Taking histories-theft by clinicians}

Medical education now stresses the importance of partnership between health professionals and patients. The hierarchical model of the doctor-patient relationship is old fashioned and inappropriate.

So why do we still tell students to "take a history" from patients? Does this phrase undermine our efforts to teach about collaboration? Shouldn't we instead "listen to people's stories"?
This would emphasise the importance of meeting the patient in his or her world and context and ensure that the start of the medical consultation does not perpetuate an outmoded and ineffective world view.

Susan M Wearne GP educator, Centre for Remote Health, Alice Springs, Australia (susan.wearne@flinders.edu.au) 